\title{
Saneamento básico e saúde pública: uma análise dos níveis de Nitrato da água consumida pela população do bairro Pajuçara - Natal/RN
}

Sanitation and public health: an analysis of the nitrate levels of the water consumed by the Pajuçara neighborhood population - Natal / RN

\author{
MOURA ${ }^{1}$, D. F. S.; TROLEIS ${ }^{2}$, A. L.; $\operatorname{SILVA}^{3}$, B. L.
} diogomourarn@hotmail.com;

\begin{abstract}
Resumo
Objetiva-se com essa discussão analisar os níveis de Nitrato da água consumida pela população do bairro Pajuçara, levando em consideração as formas de esgotamento sanitário usadas pelas pessoas que habitam nessa localidade. Para se fazer essa análise, além de uma discussão teórica sobre o assunto, foi produzido um mapa sobre os níveis de Nitrato existente na água consumida pela população, com base no método de Krigagem. Adicionou-se também a essa cartografia, informações de esgotamento básico e poços tubulares do bairro. Constatou-se nessa análise, que grande parte do bairro está consumindo água com níveis de nitrato acima do permitido pela Resoluçã CONAMA 357, o que pode está associado a localização dos poços de água que está em áreas cuja a forma de tratamento do esgoto se dá através de fossas sépticas e rudimentares.
\end{abstract}

Palavras-Chave: Esgotamento Sanitário; Nitrato; Bairro Pajuçara - Natal/RN

\begin{abstract}
Objective with this discussion analyzing the nitrate levels of the water consumed by the population of the neighborhood Pajuçara, taking into account the forms of sanitation used by people living in this locality. To do this analysis, as well as a theoretical discussion on the subject, it has produced a map of the existing Nitrate levels in water consumed by the population, based on Kriging method. also added up to this mapping, basic breakdown of information and tubular neighborhood wells. It was found in this analysis, that much of the neighborhood is consuming water above the permitted levels of nitrate, which can is associated with the location of water wells which form of treatment of sewage is done by septic tanks and rudimentary.
\end{abstract}

Keywords: Sanitation; Nitrate; Neighborhood Pajuçara - Natal / RN

\section{INTRODUÇÃO}

O saneamento básico se constitui na atualidade um dos serviços mais importante para a melhoria da saúde pública, principalmente pelo seu aspecto preventivo, no que tange à ocorrência de determinados tipos de doenças. Entretanto, o modo pelo qual ocorreu a urbanização de várias cidades brasileiras, não priorizou ações de planejamento voltadas para a melhoria da qualidade desse serviço.

Dessa forma, no âmbito do espaço citadino, o saneamento básico, é composto por: a) abastecimento de água potável; b) esgotamento sanitário, c) limpeza urbana e manejo de resíduos sólidos; e d) drenagem e manejo de águas pluviais urbanas. Esses serviços sanitários, não apresentam na maioria dos casos, um funcionamento pleno e eficiente, o que se constitui em um dos grandes desafios da questão urbana na atualidade.

Um exemplo disso é a cidade de Natal/RN, que principalmente em sua Região Administrativa Norte, apresenta baixa qualidade desse serviço. Um dos bairros mais problemáticos 
é o Pajuçara, sobretudo no que tange ao esgotamento sanitário, cuja forma de tratamento predominante é por meio de fossas sépticas e rudimentares, o que pode trazer implicações negativas para a qualidade das águas, mais precisamente, as que são provenientes de fontes subterrâneas, mais vulneráveis à contaminação por Nitrato, por exemplo. Diante disso, objetiva-se com essa discussão analisar os níveis de Nitrato da água consumida pela população do bairro Pajuçara, levando em consideração as formas de esgotamento sanitário usadas pelas pessoas que habitam essa localidade.

\section{METODOLOGIA}

A metodologia utilizada para a elaboração do trabalho, constou de dois tipos de procedimentos distintos: os de caráter teórico e os de natureza empírica.

Os procedimentos teóricos foram baseados na leitura de bibliografias especializadas em espaço urbano, saneamento básico, esgotamento sanitário, saúde pública, e qualidade de água para consumo humano. A partir dessas leituras, definiu-se três eixos temáticos de discussão: A produção do espaço urbano e o saneamento básico; o saneamento básico e saúde pública; e os níveis de Nitrato e sua relação com a qualidade de vida da população.

Atrelou-se a essa discussão teórica, os produtos gerados pelos procedimentos empíricos. $\mathrm{O}$ principal desses produtos, foi a geração de um mapa temático intitulado "Distribuição espacial dos níveis de Nitrato, da rede de esgotamento sanitário e dos poços tubulares no bairro Pajuçara". Para a elaboração desse mapa, inicialmente foram analisadas 86 contas de água, em diferentes pontos do bairro, para identificar os valores de nitrato que elas apresentavam. De posse desses valores, foi possível espacializar os dados, e interpolá-los para todo o bairro, usando o método de Krigagem (FERREIRA, 2014).

Nesse mapa, a intensidade dos níveis de nitrato foram ponderadas em cinco níveis: a) 0,72 - 3,20 mg/L; b) 3,21 - 6,00 mg/L; c) 6,01 - 10,00 mg/L; d) 10,01 - 12, $84 \mathrm{mg} / \mathrm{L}$; e e) 12, 85 - 16, $00 \mathrm{mg} / \mathrm{L}$. Esse valores foram definidos com base na resolução 357 do Conselho Nacional do Meio Ambiente (CONAMA) (BRASIL, 2005). Além disso, adicionou-se ao mapa informações (shappefile) sobre os poços tubulares e de redes de esgotamento sanitário, fornecidas pela Companhia de Águas e Esgotos do Rio Grande do Norte (CAERN, 2015). Para processar essas informações espacialmente, utilizou-se uma versão do Arc Gis, pertencente a CAERN, para a produção cartográfica.

\section{DISCUSSÃO TEÓRICA E ANÁLISE DOS RESULTADOS}

A discussão e a posterior análise dos resultados estão estruturadas em torno de três eixos de reflexão teórico-empírica: a) na primeira seção, será feita uma discussão sobre a produção do 
espaço urbano e a sua relação com o saneamento básico; b) na segunda seção, discute-se a relação entre saneamento básico e saúde pública; e c) na terceira e última seção, será feita a análise dos resultados, acerca dos níveis de Nitrato e sua relação com a qualidade de vida da população do bairro Pajuçara.

\subsection{A produção do espaço urbano e o saneamento básico}

Para se entender melhor o processo de urbanização, e a sua relação com diversos problemas socioambientais que vêm comprometendo nos últimos anos, é preciso levar em consideração a sua dimensão espacial, ou seja, o conjunto de objetos e de ações que contribuem para a produção do espaço urbano (CORRÊA, 1989; SANTOS, 2008). Diante disso, a produção do espaço urbano e a consequente urbanização está permeada por uma série de nuances, diretamente relacionadas com as ações desenvolvidas por determinados agentes.

Partindo desse princípio, a ação dos agentes produtores do espaço urbano, inclui variadas práticas, resultam em um intenso processo de reorganização territorial. Assim, ao proporcionar a reorganização do espaço da cidade, esses agentes promovem "a incorporação de novas áreas ao espaço urbano, a densificação do uso do solo, a deterioração de certas áreas, a renovação urbana, a relocação diferenciada da infraestrutura e a mudança ou não, do conteúdo social e econômico de determinadas áreas das cidades” (CORRÊA, 1989, p. 11).

Essas características da produção e reorganização do espaço das cidades, é um traço fundamental de vários núcleos urbanos do Brasil, sejam metrópoles, cidades médias ou cidades de pequeno porte. No caso da cidade de Natal, por exemplo, o processo de produção e reorganização do espaço urbano foi condicionado pela ação do poder público, principalmente, por meio da implantação de conjuntos habitacionais, e pelo capital industrial, com a instalação de empreendimentos fabris, sobretudo, na Região Administrativa Norte da cidade (LIMA e SILVA, 2000).

A construção do Distrito Industrial de Natal, aliado a implantação de conjuntos habitacionais, nas décadas de 1960, 1970 e 1980, foram grandes incentivos para o adensamento populacional de área de forma rápida, o que contribuiu para o surgimento de vários bairros (LIMA e SILVA, 2000). Um desses bairros foi o de Pajuçara, que começou a surgir a partir da década de 1990, tornando-se uma das principais áreas de instalação da população carente, proveniente do interior do estado do Rio Grande do Norte. Vale lembrar, que a produção do solo urbano desse bairro foi motivada não só pelos conjuntos habitacionais, mas também, pelo surgimento de loteamentos e de áreas de ocupação irregular (AZEVEDO, 2010; SILVA, 2003).

A parte do bairro considerada de ocupação irregular é a comunidade da Pompéia, onde existem aproximadamente 2.600 domicílios particulares ocupados, tornando Pajuçara, o segundo 
bairro da Região Administrativa Norte com a maior população residente em domicílios particulares ocupados. De acordo com as estimativas, no ano de 2013, haviam no bairro pouco mais de 68.000 habitantes, fato que tende a influenciar o aumento da demanda populacional sobre os serviços básicos de consumo coletivo (SEMURB, 2014).

Nesse sentido, com o aumento dessa demanda populacional, juntamente com a má administração do bairro, por parte dos órgãos públicos, tende a haver uma precarização dos equipamentos de consumo coletivo, fazendo com que a população venha a sofrer com uma série de problemas, dentre eles a ineficácia do serviço de saneamento básico. Cabe destacar, que a finalidade primordial desse serviço é a de diminuir ou eliminar qualquer efeito prejudicial a saúde, como a contaminação da água e a consequente transmissão de doenças, tendo em vista proporcionar uma melhor qualidade de vida à população. Por esse motivo, há a necessidade de se discutir mais aprofundadamente as condições de saneamento básico do bairro Pajuçara, e sua relação com a saúde pública.

\subsection{Saneamento básico e saúde pública}

Saneamento básico e saúde pública compreendem uma relação que vem sendo disseminada pela sociedade desde as civilizações clássicas, pelos povos antigos que viviam nas cidades da época. Desse modo, durante a história da humanidade determinadas ações higienistas, como as ligadas a engenharia e a medicina, foram desenvolvidas pelas civilizações romana, grega e egípcia. Pode-se dizer assim, que as ações idealizadas nesse período, foram o "ponta pé inicial" para o desenvolvimento de projetos mais avançados, no âmbito do saneamento básico (SOTERO, 2010).

Assim como, nas civilizações clássicas, na atualidade o saneamento básico é considerado uma das principais ferramentas da geração de qualidade de vida de uma população. Seu objetivo é impedir que doenças de veiculação sanitária, sejam adquiridas pelo ser humano, o que poderá resultar na redução dos índices de morbidade das pessoas, no que se refere a doenças de veiculação hídrica. Nesse sentido, a Organização Mundial de Saúde (OMS), define saneamento como o controle de todos os fatores do meio físico que exercem ou podem exercer efeitos nocivos sobre o bem estar físico, mental e social (BRASIL, 2004a).

Para que esse controle seja exercido de maneira adequada, o saneamento básico deve levar em consideração quatro elementos constituintes, tal como estabelece a lei $\mathrm{N}^{\circ} 11.445 / 2007$. Os quais sejam: a) abastecimento de água potável; b) esgotamento sanitário, c) limpeza urbana e manejo de resíduos sólidos; e d) drenagem e manejo de águas pluviais urbanas (BRASIL, 2007).

Com relação ao sistema de abastecimento de água potável, ele é caracterizado pelas atividades, infraestruturas e instalações necessárias ao abastecimento público de água potável, tendo como etapa inicial a captação, e como etapa final a distribuição da água para o consumo da 
população. Essa forma de sistema de abastecimento segue o padrão tradicional, mas é importante destacar que existem outras formas de abastecimento de água, como por exemplo, as que utilizam veículo transportador, poço comunitário, ou até mesmo as instalações condominiais horizontais e verticais (BRASIL, 2006; BRASIL, 2007).

Outro elemento do saneamento básico é o esgotamento sanitário, composto pelas atividades de operacionais de coleta, transporte, tratamento e disposição final adequados dos esgotos sanitários, desde a sua origem nas ligações prediais e residenciais, até o seu lançamento final no meio ambiente (BRASIL, 2007). É importante destacar que existem diferentes formas de esgotamento, as mais usadas são as fossas e os sistemas de redes coletoras, que visam promover novos hábitos higiênicos na população e oferece conforto e senso estético para esta (SPERLING, COSTA e CASTRO, 1995).

Além do esgotamento sanitário, outro elemento integrante do saneamento é a limpeza urbana e o manejo de resíduos sólidos. Trata-se de um conjunto de atividades responsáveis pela coleta, transporte, tratamento e destino final dos resíduos sólidos gerados pela população, em suas diversas atividades cotidianas (BRASIL, 2007). Esses resíduos são compostos por "matérias heterogêneos (inertes, minerais e orgânicos), podendo resultar em problemas sanitários, econômicos e principalmente estéticos", caso não sejam manejados de forma correta (BRASIL, 2004b, p.227).

E por fim, o último elemento componente do saneamento básico, que é a drenagem e manejo das águas pluviais urbanas. A função das estruturas de drenagem urbana é a de proporcionar o transporte, a detenção e retenção das águas para o amortecimento de vazões de cheias, com vistas a evitar alagamentos no espaço das cidades. Essas estruturas são importantes no espaço das cidades em função da grande quantidade de áreas impermeabilizadas, o que tende a diminuir a infiltração da água no solo, havendo assim a necessidade de canais para o seu escoamento e deposição em locais específicos (BRASIL, 2007).

Assim, é a partir do funcionamento correto e eficiente desses quatro elementos que o saneamento básico pode apresentar maior capacidade de cumprir com a sua função principal, que é a de diminuir a incidência de doenças de veiculação hídrica e de melhorar a qualidade de vida da população (BRASIL, 2004a). Entretanto, nem sempre há um funcionamento correto e sincrônico dos quatro elementos componentes do saneamento básico, sendo possível identificar uma série de problemas dessas estruturas em várias cidades a nível nacional e regional.

Uma das questões que tem mais preocupado, no que tange ao saneamento básico das cidades brasileiras, é a precariedade do serviço de esgotamento sanitário, principalmente nos bairros com população mais pobre. Nesses bairros, a forma de esgotamento predominante é por meio de fossas, de forma rudimentar, o favorece a infiltração dos dejetos no lençol freático, pelo processo de 
percolação, podendo poluir poluindo os mananciais subterrâneos e superficiais, de onde se retira água para o abastecimento humano (BRASIL, 2004b).

Dessa forma, a ineficiência das estruturas de esgotamento sanitário, principalmente por meio de fossas, ao invés de redes coletoras, acaba comprometendo um outro elemento do esgotamento sanitário, o sistema de abastecimento de água. Uma das prerrogativas funcionais do sistema de abastecimento é a distribuição de água em quantidade e qualidade compatíveis com as necessidades da população, ou seja, dentro dos padrões de potabilidade permitidos para o consumo humano (BRASIL, 2004b).

Porém, quando a água encontra-se poluída, em função do contato com dejetos, uma série de substâncias (indicadores) biológicas e químicas acabam apresentando concentrações acima do limite permitido. Do ponto de vista biológico, destacam-se como indicadores, as bactérias, os fungos, os protozoários e as algas. Uma das bactérias mais usadas como indicador, são os coliformes, "típicas do intestino humano e de outros animais de sangue quente (mamíferos), e por estarem presentes nas fezes humanas (100 a 400 bilhões de coliformes/hab.dia), são adotadas como referência para indicar e medir a grandeza da poluição" (BRASIL, 2004b, p.155 a 156).

Do ponto de vista químico, os esgotos domésticos e industriais acabam resultando em substâncias como Nitrogênio, Fósforo e Nitrato. No caso do Nitrato, de acordo com a resolução CONAMA n 357 de Março de 2005 (BRASIL, 2005), o limite máximo permitido para as águas doces destinadas ao abastecimento humano é de 10,0 mg/l. Concentrações acima desse valor podem provocar sérios problemas de saúde para o ser humano.

Essa associação entre esgotamento sanitário e qualidade da água para o abastecimento, pode ser feita para o bairro Pajuçara. Nesse bairro da Região Administrativa Norte da cidade de Natal, quase $100 \%$ da população não dispõe de esgotamento sanitário baseado em redes de coleta, tendo como principal forma de tratamento as fossas rudimentares (SEMURB, 2013). Sabendo que parte da água consumida nesse bairro é proveniente de poços tubulares, que estão implantados na própria localidade, pergunta-se: quais os níveis de nitrato existente na água consumida pela população desse bairro?

Para responder a essa questão, e com isso lançar hipóteses sobre a relação entre esgotamento e sistema de abastecimento, faz-se necessário desenvolver uma análise dos níveis de nitrato registrados pela Companhia de Águas e Esgotos do Rio Grande do Norte (CAERN, 2015), nas diferentes regiões do bairro.

\subsection{Os níveis de Nitrato e sua relação com a qualidade de vida da população}

As águas responsáveis pelo abastecimento do bairro Pajuçara, são provenientes de duas fontes distintas: aproximadamente $60 \%$ da água distribuída é proveniente da Lagoa de Extremoz, 
enquanto que os outros $40 \%$ são oriundos de poços tubulares que captam água do aquífero Dunas/Barreiras, que totalizam 52, sendo que apenas 33 estão em operação (CAERN, 2010).

O fato de quase metade da água consumida no bairro ser de origem subterrânea gera preocupação com a qualidade de vida de todos aqueles que a consomem, isso porque, somente $1,60 \%$ desta população é atendida pela rede geral de esgoto. Assim, o restante dessa população, acaba utilizando outras formas de esgotamento sanitário em suas residências, tais como as fossas sépticas ou rudimentares (SEMURB, 2013).

Dada essas características do sistema de abastecimento de água e de esgotamento sanitário, aliada a condição pedológica da área, que é caracterizada por solos arenosos, de alta permeabilidade (SEMURB, 2013), a qualidade da água consumida pela população do bairro tende a ser duramente afetada. E para identificar as prováveis alterações de qualidade nessa água, será utilizado como indicador os níveis de Nitrato registrados pela CAERN (2015), em diferentes áreas do bairro atendidas pelo sistema de abastecimento.

Para compreender melhor o padrão de distribuição espacial dos níveis de Nitrato, da rede de esgotamento e dos poços tubulares no bairro Pajuçara, foi produzido um mapa temático (figura 1), a partir da aplicação do método de Krigagem (FERREIRA, 2014)

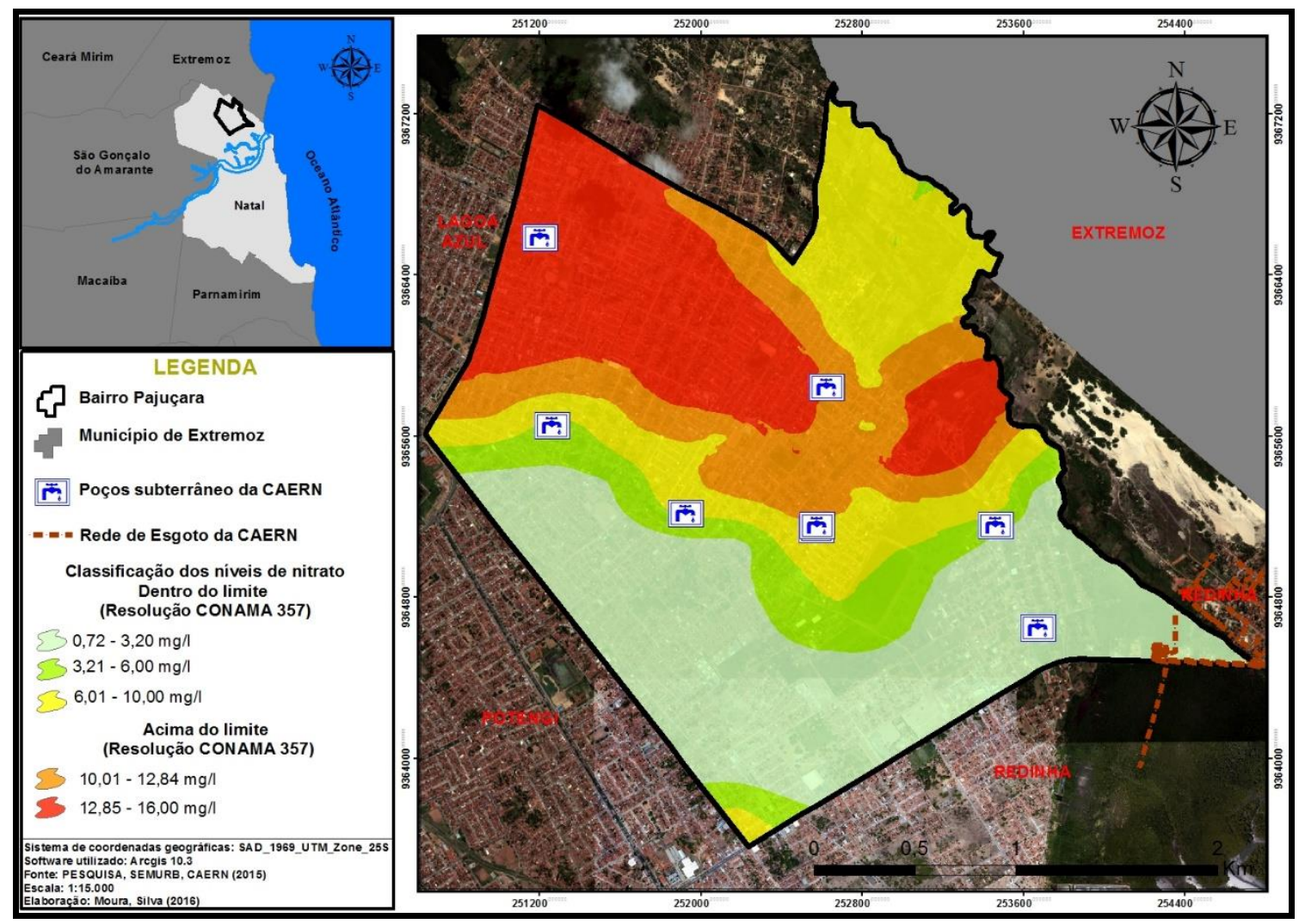

Figura 1: Distribuição espacial dos níveis de Nitrato, da rede de es gotamento sanitário e dos poços tubulares no bairro Pajuçara. Fonte: elaborado por Moura e Silva (2016), com base nos dados da CAERN (2015) e SEMURB (2014). 
Com base na análise do Figura 1, pode-se perceber que a rede de esgotamento sanitário do bairro Pajuçara está restrita a uma pequena área, localizada na divisa com o bairro Redinha. Diante disso, conclui-se que a maior parte do bairro Pajuçara encontra-se sem as redes de esgotamento sanitário, o que implica na utilização de outras formas de processamento do esgoto gerado, tais como fossas sépticas e rudimentares.

O fato de existirem muitas fossas sépticas e rudimentares pelo bairro pode implicar em uma série de problemas com relação à qualidade do abastecimento de água para a população, principalmente no que diz respeito à qualidade das águas subterrâneas, dos poços tubulares. Conforme mostra o Figura 1, no bairro Pajuçara existe um total de 7 poços tubulares ativos, os quais são responsáveis pelo abastecimento de parte da população.

Essa conjuntura, apresentada pelo bairro, caracterizada por um lado, pela falta de redes de esgotamento sanitário e pela existência de poços tubulares usados para o abastecimento de água, localizados nessa mesma área, torna essa área vulnerável à contaminação da água de seu lençol freático, principalmente por Nitrato (BRASIL, 2004b). Para entender melhor essa questão, busca-se elucidar os passos desenvolvidos para obtenção da figura 1. Após a análise laboratorial realizada pela CAERN, da água distribuída em cada setor do bairro Pajuçara e dispondo dos resultados do Nitrato, foi gerado através do método de Krygagem uma cartografia espacializando os níveis de ocorrência do fenômeno que chega para o consumo da população local.

A resolução CONAMA 357, estabelece os níveis de nitrato toleráveis para serem consumidos pelos seres humanos, em água, o que equivale a $10 \mathrm{mg} / \mathrm{L}$ (BRASIL, 2005). Com base nesse limite legal, espacializou-se os níveis de nitrato no bairro Pajuçara, a partir da definição de cinco categorias: a) $0,72-3,20 \mathrm{mg} / \mathrm{L}$; b) $3,21-6,00 \mathrm{mg} / \mathrm{L}$; c) $6,01-10,00 \mathrm{mg} / \mathrm{L}$; d) $10,01-12,84$ $\mathrm{mg} / \mathrm{L}$; e e) $12,85-16,00 \mathrm{mg} / \mathrm{L}$.

Analisando a figura 1, é possível destacar duas áreas específicas, a que está na cor laranja representando uma concentração de Nitrato na água de $(10,01$ - 12,84 mg/L) e a que está na cor vermelho representando a concentração de Nitrato na água de $(12,85$ - 16,00 mg/L). Essas duas áreas correspondem aos setores do bairro que estão consumindo água acima dos padrões de potabilidade permitidos, no que se refere aos níveis de Nitrato. Trata-se de duas áreas consideradas de alto risco, no que tange à qualidade da água consumida, haja vista que o consumo de nitrato nesses níveis pela população durante um longo período podem acarretar uma série de problemas de saúde. Outro aspecto em destaque são as áreas que apresentaram concentrações de Nitrato dentro do limite permitido pela Resolução CONAMA 357. Apesar de não contrariarem a legislação, são áreas consideradas de risco médio, porque a água distribuída a população não apresenta boa qualidade, sendo essas representadas na figura 1 pelas cores Amarelo e Verde. 
Além disso, nota-se também a existência de poços tubulares que são utilizados pela CAERN para abastecimento de água do próprio bairro Pajuçara, o que exige do poder público, uma atenção especial na resolução desse problema, tendo em vista o risco de poluição da água desses poços pelos dejetos das fossas. Por esse motivo, os problemas relacionados a poluição das águas potáveis em função da falta ou insuficiência do serviço de esgotamento sanitário, trata-se de uma questão de saúde pública, que merece atenção especial dos planejadores e gestores das cidades.

\section{CONSIDERAÇÕES FINAIS}

O processo de produção do espaço urbano em várias cidades brasileiras, dentre elas Natal, apresentou uma série de contradições de natureza estrutural, como por exemplo, os problemas relacionados à qualidade do serviço de saneamento básico. Para serem resolvidos, é necessário que haja um planejamento das ações a serem feitas no contexto do espaço urbano, uma vez que, a resolução dos problemas ligados ao saneamento básico pode significar um investimento de suma importância para melhoria da saúde da população.

No caso de Natal, especificamente, um dos elementos do saneamento básico que tem apresentado muito problemas é o sistema de esgotamento sanitário. Usando como estudo de caso o bairro Pajuçara, localizado na Região Admistrativa Norte dessa cidade, foi possível constatar que a predominância de formas de esgotamento baseadas em fossas sépticas e rudimentares, pode ter ligação direta com os altos índices de nitrato observados na água consumida por parte da população.

Dessa forma, a existência de nitrato acima do permitido $(10 \mathrm{mg} / \mathrm{L})$ em águas consumidas pela população do bairro, pode ser associada a problemas relacionadas a duas esferas de gestão: no âmbito do planejamento urbano e no âmbito da saúde pública. Diante disso, recomenda-se que para a resolução ou atenuação desse problema, os planejadores do espaço urbano possam trabalhar de forma integrada com os profissionais do ramo da saúde pública, uma vez que, as doenças geradas pela grande quantidade do nitrato consumido em água é consequência, na maioria das vezes, do não investimento em redes de esgotamento sanitário.

\section{REFERÊNCIAS}

AZEVEDO, Pablo Guimarães. Vulnerabilidades socioambientais na zona de proteção ambiental - 9 Natal/RN/. Dissertação apresentada ao Programa de Pós-Graduação e Pesquisa em Geografia da Universidade Federal do Rio Grande do Norte, Natal, 2010.

BRASIL. Ministério da Saúde. Organização Pan-Americana da Saúde. Avaliação de impacto na saúde das ações de saneamento: marco conceitual e estratégia metodológica. Organização PanAmericana da Saúde. - Brasília: Ministério da Saúde, 2004a.

BRASIL. Manual de Saneamento. Brasília: Fundação Nacional de Saúde, 2004b.

BRASIL (2005). Ministério do Meio Ambiente. Conselho Nacional do Meio Ambiente (CONAMA). Resolução No 357, de 17 de Março de 2005. Dispõe sobre a classificação dos corpos 
de água e diretrizes ambientais para o seu enquadramento, bem como estabelece as condições e padrões de lançamento de efluentes, e dá outras providências.

BRASIL. Fundação Nacional de Saúde (FUNASA). Manual de Saneamento. 3. Ed. Ver. - Brasília. Ano. 2006

BRASIL (2007). Lei 11.445 de 5 de janeiro de 2007. Estabelece diretrizes básicas para o saneamento básico. Brasília: Congresso Nacional, 2007.

COMPANHIA DE ÁGUAS E ESGOTOS DO RIO GRANDE DO NORTE (CAERN). Dados do Sistema de Água e Esgoto 2010. Disponível em: http://www.caern.rn.gov.br. Acesso em: 22 Fev. 2012.

COMPANHIA DE ÁGUAS E ESGOTOS DO RIO GRANDE DO NORTE (CAERN). Dados do Sistema de Água e Esgoto 2015. Dados obtidos junto aos arquivos da CAERN, mais precisamente no escritório da Regional Zona Norte.

CORRÊA, Roberto Lobato. O espaço urbano. São Paulo: Ática, 1989.

FERREIRA, Marcos César. Iniciação a análise geoespacial: teoria, técnicas e exemplos para geoprocessamento. São Paulo: editora Unesp, 2014.

LIMA E SILVA, P.P. Dicionário Brasileiro de ciências ambientais. São Paulo: Editora Thomson Learning edições, 2000.

SANTOS, Milton. A natureza do espaço: técnica e tempo, razão e emoção. Santos. São Paulo: Editora da Universidade de São Paulo, 2008.

SECRETARIA MUNICIPAL DE MEIO AMBIENTE E URBANISMO (SEMURB). Anuário Natal. Natal, 2014.

SECRETARIA MUNICIPAL DE MEIO AMBIENTE E URBANISMO (SEMURB). Anuário Natal. Natal, 2013.

SILVA, Alexandro F. Costa. da. Depois das fronteiras: a formação dos espaços de pobreza na periferia norte de Natal-RN. Dissertação apresentada ao Programa de Pós-Graduação em arquitetura e urbanismo da Universidade Federal do Rio Grande do Norte, Natal, 2003.

SOTERO, Aglene de Arruda Moreira. O esgotamento sanitário e o uso do território em Natal/RN (1969 - 2009). Dissertação apresentado na Universidade Federal do Rio Grande do Norte, no Programa de Pós-Graduação e Pesquisa em Geografia. 2010.

SPERLING, Marcos Von; COSTA, Ângela Maria Ladeira Moreira da; CASTRO, Alaor de Almeida. Capítulo 5: Esgotos Sanitários. In.: BARROS, R. T. V. et al. Manual de saneamento e proteção ambiental para apoio aos municípios. Departamento de Engenharia Sanitária e Ambiental -DESA/UFMG. Fundação estadual do Meio Ambiente - FEAM. Belo Horizonte: Escola de Engenharia da UFMG, 1995.

Recebido em: 14/08/2016

Aceito para publicação em: 01/10/2016 